\title{
Diffusion of Strategic Practices in HRM and their Impact Over Productivity of Small Firms
}

\author{
Shobha Bhardwaj, Ajay Jain, Vinay Kumar
}

\begin{abstract}
With the change in time, the practices of HR also get changed to support the businesses in the highly competitive market like by incorporating the technology in daily workplace activities. Although the incorporation of new techniques and methodologies in HR was very limited in past few decades but after analyzing the benefits in every area, HR department incorporate these into their daily functioning like the use of SHRM, HRIS. HRIS system is an application of technology where big data can be managed, retrieved easily by replacing the heavy filing paper work and gives error free result. In this paper after the deep review of literature, the researcher selected six human factors based on infusion of technology in HR practices and their impact over the productivity. This study is conducted to put some light over the technology benefits in small firms, which are lacking in the previous studies. Maximization of profit, high production, good quality and customer satisfaction are the current requirements of every company and to fulfill these requirements technology plays a vital role. Analysis of the information collected from the sample in this research study clearly revealed that requirements of a company could be fulfilled by choosing some selective HR practices along with the strategic point of view for optimization of productivity. PLS-SEM software is used to calculate the statistical value of variables in precise form to analyze this new combination of technology and HR. So, this paper applying quantitative structural analysis method of PLS software to find out the rationale of the study by supporting the concept of right selection of innovative information system in HR practices based on human factor leads to great result.
\end{abstract}

Keywords : SHRM, HR Practice, productivity, human factor, HRIS, PLS-SEM.

\section{INTRODUCTION}

In the current scenario any functional discipline cannot work alone without in touch with the new techniques. Due to tremendous growth and results of IT, HR functional area also adopts it in their daily working processes either directly or indirectly. HR practices infused with technology play a significant role in increasing the productivity of any organization. The strategic HR practices considers the organization as whole and apply the practice based on the market requirement which helps to gain the long-term success of any business. Every researcher used different phenomena to prove their statement that the HR practices play a vital role towards achieving the best results. Same in this paper the researcher is trying to select few human factors based innovative HR practices for interpreting the result of this study.

Strategic HR practice means applying the best manpower management activities so that the output, performance and

Revised Manuscript Received on September 25, 2019

Shobha Bhardwaj, Research Scholar, Department of Management Studies, SRM Institute

Dr. Ajay Jain, Department of Management Studies, SRM Institute

Dr. Vinay Kumar, Associate Professor, Chandigarh University, Mohali skills of manpower of any organization can be improved. Mayhew (2018) stated that these practices having powerful effect over the manpower of any organization and these practices can be generated inside the organization or can be availed from outside sources by outsourcing their HR work from the third parties like recruitment, training, work life balance etc.

Based on the previous literature review it is clearly seen that it is very difficult for researcher to generate HR Practices impact over dependent variable in quantitative terms although in this research paper the researcher is trying to resolve this problem by applying the structural equation model and conclude the result in quantitative terms. The blend of new practices in HR is in various forms mentioned below:

- Salaries and other payment directly transferred into employee account

- Performance of the employees can be easily evaluated in quantitative term by using software

- HR planning can be easily done by using suitable forecasting statistical tool

- Training can be done online based on competency mapping

- Salary and other compensation work can be easily done by using payroll software

- Recruitment and selection can done easily by using online Skype interview method

- Data can be managed easily online which reduce the paper cost

- Employee attendance machine for online thumb impression or card scanner

The researcher also expecting that the results of this research study can be interpreted in approximate value which can provide the relevant information to the company's who are facing the problem or myth that HR practices diffusion really support in enhancement of productivity or just cost increasing burden over the company.

\section{LITERATURE REVIEW}

The literature part helps the researcher in clearing their view towards the HR practices and their applicability in small firms. Based on the literature review the researcher selected various human factors for this study over which various items are generated for scale development and statistical analysis. The beginning of the literature review starts with the human factors related reviews of other researchers.

Bell (2006) stated in her research paper about the impact of four constructs, i.e. work related factor, personal factor, technology and organizational factor and each factor are then further subdivided into many other variables. These variables 
impact are checked over the productivity. The researcher highlighted the role of some selective HR practices like working culture related and incentive plans practice of HR which are also helpful in achieving the right level of productivity. Wright, Gardner, \& Lisa (2003) considered two important factors, i.e.HR practice and attachment of employee with their organization to measure the productivity as well as performance of their firm. Human Resource practices choose by the researcher in the form of factor are selection, training, performance, employee participation and these practices are then further subdivided into variables to measure their role over the productivity. The conclusion of this study stated a positive relation over the productivity and the HR practices which were selected previously for this study. Singh (2004) identified two key important dependent factors i.e. organization performance and market performance over which the two HR practices i.e. training and compensation practices impact were measured in 84 Indian companies. His study concluded that the proper use of HR practices that are based on the requirement could lead to achieve the satisfactory level of output for any company. Singh R. K. (2009) identified a positive correlation between the welfare measure practices adopted by the company as per the factories act 1948 and labor productivity. The outcomes of this study identified that after provided the comfortable working environment as a welfare practice can make employees happy while doing their work because generally the workers don't like the work and taken as burden. The welfare facility chooses by the company should be based on the requirement raised by their employees rather than randomly imposing on them.

Bun \& Huberts (2018) identified two factors based on compensation i.e. high pay and low bonus for their research study. This research shows a clear impact over productivity due to change in the pay structure of their employees like when the company was using the fixed pay concept, the productivity going decreased because employee are more satisfied in getting the bonus or incentives based on their performance rather than a fixed pay which they get every month earlier. Abdulai \& Shafiwu (2014) clearly highlighted in their research study the connectivity exist between employee participation in decision making and the productivity of a company by defining as well as showing their benefits The application of different types of participation techniques used by companies will results in various types of outcomes like employee satisfaction, employee commitment etc. Onyije (2015) identified a significant relationship in measuring and implementing certain criterion-based methods of appraisal based on the employee performance and productivity in different institution of Nigerian University. The researcher identified that performance criteria should be based on the performance of employees rather than based on the personal traits. The scale was developed based on traits played a significant role towards the good employee performance, satisfaction and increased productivity. Efficiency can be increased in any firm by the application of technology, which enables the proper assessment of employee as well as in maintaining the performance data of employee at one place (Ahmed, 2016) Flores (2017) signifies in his research that technology having a tremendous effect over the productivity because it caters wide variety of benefits to the business. The application of technology are in the form of data management system, employee administrative task management, employee customized reporting preparation etc. A wide variety of applications have been served by the technology that is incorporated in the companies in varieties of form, but the implementation of IT requires a proper HR department in form of HRIS software, which helps the company to manage their day-to-day difficult task in an easier way. Stone, Deadrick, Lukaszewski, \& Johnson (2015) stated in his research article about the impact and importance of technology with reference to HR practices. The researcher used various technical terms in his study with their impact and limitations like e-recruitement, online job analysis, electronic resume invitations and their short listings but at the end in conclusion part the outcome of their study was the technology changes the older version of HR into the eHR form and this her concept will increase in future. Sarangi \& Nayak (2016) clarify the role of employee engagement in the form of employee potential towards their work. The researcher identified the impact of these practices over the productivity of a company. Employees agrees that after applying the six C's as a measuring parameter over their responses can really helps in boosting up their work related passion and increasing their morale towards the effective success of any manufacturing sector. Ichniowski, Shaw, \& Prennushi (1995) identified some effective employment HR practices like job rotation, flexible timing etc.in the form of independent variables for his research study over which the dependent variables i.e. productivity was checked by applying the correlation method. The result interpretation of this study is based on incentive plans and practices which are having the direct impact after comparing with other HR practices role over the employee performance.

Pandey (2018) stated the importance of artificial concept benefit in HRM. The researcher stated that the replacement of humans with the machines creates a machine learning environment and can work fast, error free without the involvement of humans in an easy way.

Florkowski \& Lujan (2006) stated the importance of technology in HR department of US firms and for this study the researcher selected the eight HR blend technology application with their importance.

Katou \& Budhwar (2015) identified the role of some selected HR practices like incentive plans and compensation practice. These practices result a positive change in the productivity of an organization and impact over the empirical value by preparing a HRM model. The researcher stated that the competitive advantage could be gained by applying good incentive plan, training methods rather than focusing only on decreasing the burden over the company by cutting the cost or by decreasing the employee wages.

Ulrich (1997) stated the result of his research in quantitative terms that are based on some selected HR practice and also clears the myths that results interpretation of HR practices is hard to be measured in value form. The researcher clearly stated that by applying suitable HR models anyone can measure the HR work in quantitative value form by applying the suitable measurement technique i.e. balance score card and $H R$ audit in the form of HR practices

Gamage (2015) stated that labor efficiency and productivity can be raised by proper use of available manpower resources and by applying the HR practices in small medium size enterprises. These HR practices are staffing, training and development, performance evaluation, compensation management techniques. The 
empirical model used in this study is mentioned below:

Source: (Constructed by Gamage (2015)

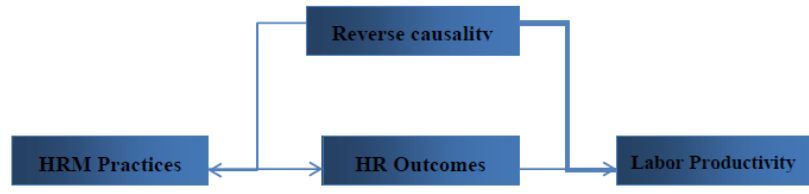

Figure 1: A Simple HR process model

Casse, Nadin, Gray, \& Clegg (2002) used two methods for getting information collection from employees i.e. telephone and face to face interview about the HR practices used by SME's in Europe. The outcome of this study was that the reward was the least used HR practice and the most liked HR practices were employee empowerment.

Many small scale companies generally avoid the application of HRM practices but these practices having the tremendous long term impact over small as well as large scale companies (Bhardwaj \& Jain, 2019).

Sea (2017) identified few HR practices to measure the productivity at workplace. A happy and satisfied employee can work freely without any tension by giving their $100 \%$ efforts. HR practices to measure the productivity used in this paper are mention below:

1. Used employee survey methods to know about their feeling related to workplace

2. Take review from employees regarding the working environment facility

3. Identify the connection between the workplace timing flexibility and productivity

4. Impact of technology over productivity

5. Employee potentiality can be induced by creativity

Singh, Darwish, Costa, \& Anderson (2012) link the HRM practices with the performance of the organization and employee desired behavior by considering external, internal, direct and indirect factors over which a conceptual framework model has been developed. These factors are mentioned below:

Internal factors are: HR practices, Motivation, Leadership, Organization structure, size of organization, marketing strategies

External factor: market structure, competitive environment, political and social environment, and industry incentives.

The literature review part of this research paper described above is based on some selective HR factors and each researcher highlighted the importance of its chosen factors by connecting it with the employee and productivity concept. The outcome of their research may be suitable in one company but it is also possible that the same outcome may not be received while applying the same practice in other company.

\section{DESCRIPTION ABOUT THE CONCEPTUAL MODEL}

This conceptual model is perfectly suitable to assemble all the details mention in the literature part of this paper in one frame to find out the rationale of this study.

These are seven factors selected by the researcher based on their own requirement and literature review, which are mentioned below;

1. Employee Satisfaction: It is the effect of the combination of all three items i.e. stress, motivation, attitude.

2. Payment Structure: High pay low bonus timely pay combined together to form the payment structure of employee compensation.

3. Employee Participation: Informal, consultative, ownership are the three practices of HR by which an employee can participate in company decision-making.

4. Performance Appraisal: Improvement plan, quality, self-evaluation, performance record are three constraints which constitutes the performance appraisal practice of HR.

5. HRIS: IT is a part of every field in a business and it also contributes in HR in the form of Payroll, data manage, self-service and Artificial Intelligence like intelligent software system.

6. Employee Engagement: These are the practices that encompass the involvement of employees in company matters in the form of collective bargaining or employee participation that results in trust building, personal growth and commitment among employees.

7. Productivity: The combination of all other factors discussed above results in high productivity. The outcome of these factors is in the form of creativity, employee satisfaction, market share, better quality and competitive advantage.

This model clearly highlighted the importance of the factor, which is related to the humans working in the company in the form of human factors. These human factors are developed and implemented by the HR department of a company. The result of these factors combinations along with their sub factors constitutes a fruitful result in the favor of company and employees.

The result of this model may vary because every company has its own working culture and environment. Depending upon the suitability these factors, these practices can be applied. This model has been further analyzed and modified by Smart PLS analysis to verify their applicability. 


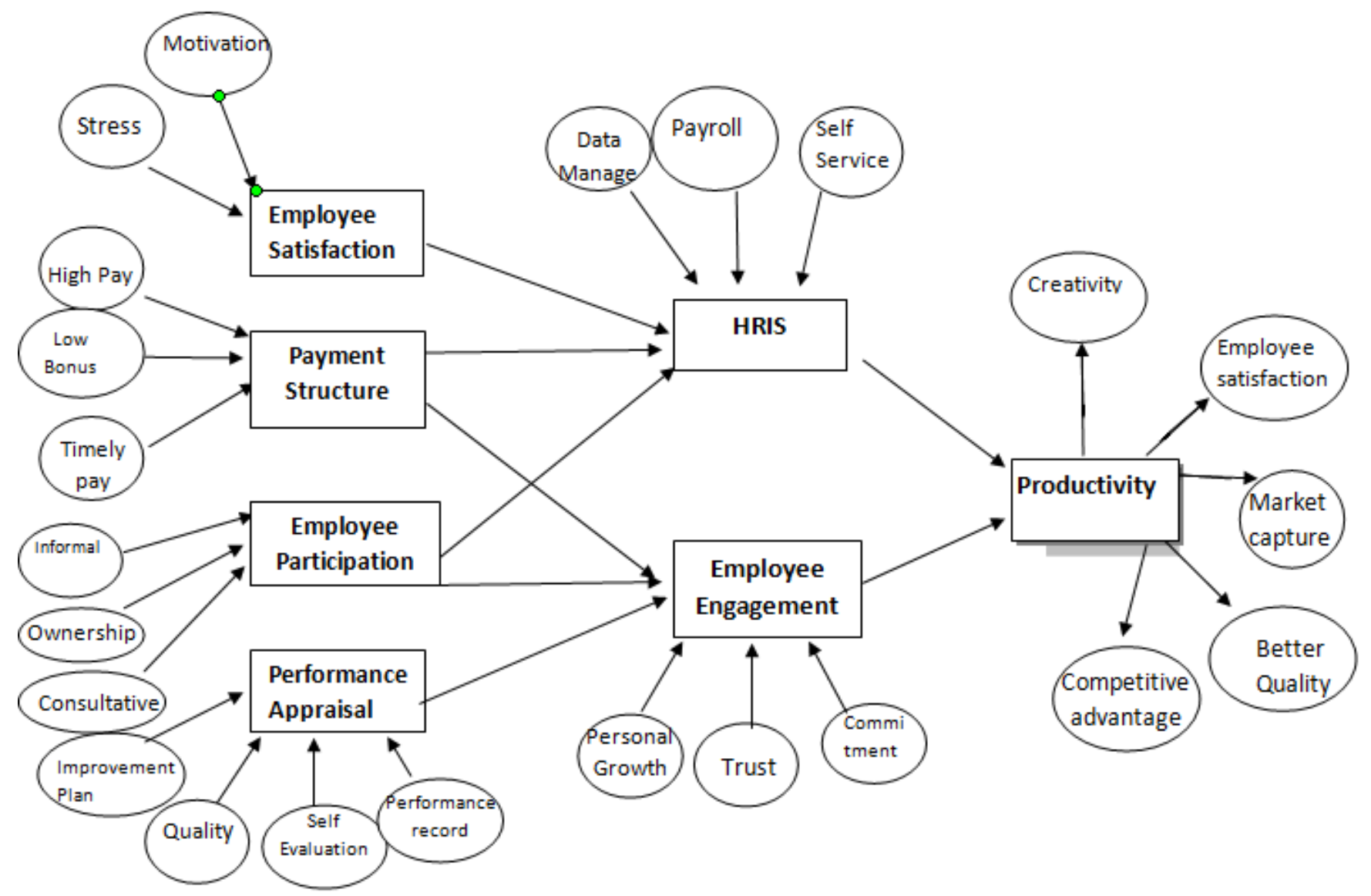

Source: Payment structure by Bun \& Huberts (2018), Employee Participation by Abdulai \& Shafiwu (2014), Employee satisfaction by Onyije (2015), Performance Appraisal by Onyije (2015), HRIS by Flores (2017), Employee Engagement by Sarangi \& Nayak (2016)

Figure 2: Structural Model of HR practice along with its variables impact over the Productivity.

\section{RESEARCH METHODOLOGY}

Objective: There is one main objective of this paper along with some other sub objectives, mentioned below:

1. To identify impact over the HR practices and productivity of small firms by invasion on new methodologies.

2. To identify the six human factors based practices impact by infusing with new methods and their result over the productivity in different forms.

3. To highlight the importance of right selection in HR practices that is based on company requirement.

Hypothesis: The hypotheses set by researcher based on their study requirement are stated below:

H1: Technological development having a tremendous effect over the productivity of employees

$\mathrm{H} 2$ : Employee engagement practice helpful in increasing the support of employees towards their organization.

H3: Traditional practices result get increased after getting in touch with the technology

H4: Technological development is very helpful in nurturing the small firms by selecting the right suitable method

Research Design: For this research paper study, we are using the descriptive research design as well as exploratory research design. By identifying the modern HR practices as in the form of constructs, which are further subdivided into the variables form to describe research problem and their level of impact over the productivity

Sampling type: For this research study, probability-sampling method has been used for this research. In probability sampling method, we opt the random sampling method for selecting the sample from population, which is representing the whole population.

Scale development: For scale development for this research study, we selected the six constructs based on the past literature, which are further subdivided into 24 variables. For this research, seven point Likert's scale has been used in which 1 point resemble for Strongly Disagree while point 7 shows the Strongly agree opinion. All the constructs along with their variables references are mentioned below:

Career Planning (Singh K. , 2004), Employee welfare (Singh R. K., 2009), Payment structure (Bun \& Huberts, 2018), Employee Participation (Abdulai \& Shafiwu, 2014), Performance Appraisal (Onyije, 2015), HRIS (Flores, 2017), Employee Engagement (Sarangi \& Nayak, 2016). Variable which are designed based on the constructs are work attitude, motivation, stress, high pay, low bonus, timely pay, informal, consultative, ownership, improvement plan, quality, self-improvement,

performance record, Payroll, data management, self-service, personal growth, trust, 
commitment choose by researcher a per their requirement and last five variables i.e. creativity technology, employee survey, flexible work time flexible timings (Sea, 2017).

Sample size and sample area: The sample size chose for this study is about 100 respondents and the sampling area for response collection is managerial level full time permanent employees of manufacturing sector of electrical goods small and medium size firms are used.
Data Collection: Data collection has been done by the two methods for this research study mention below:

Primary data collection: Primary data collected by using the questionnaire, schedules and the direct interview of the experts and the managers of the companies.

Secondary data collection: Secondary data collected by using the literature review of previous research, books, journals and online available resources.

\section{DATA ANALYSIS}

The model has been described by using the PLS-SEM tools. The online software generated results are shown in the diagrammatic representation below:

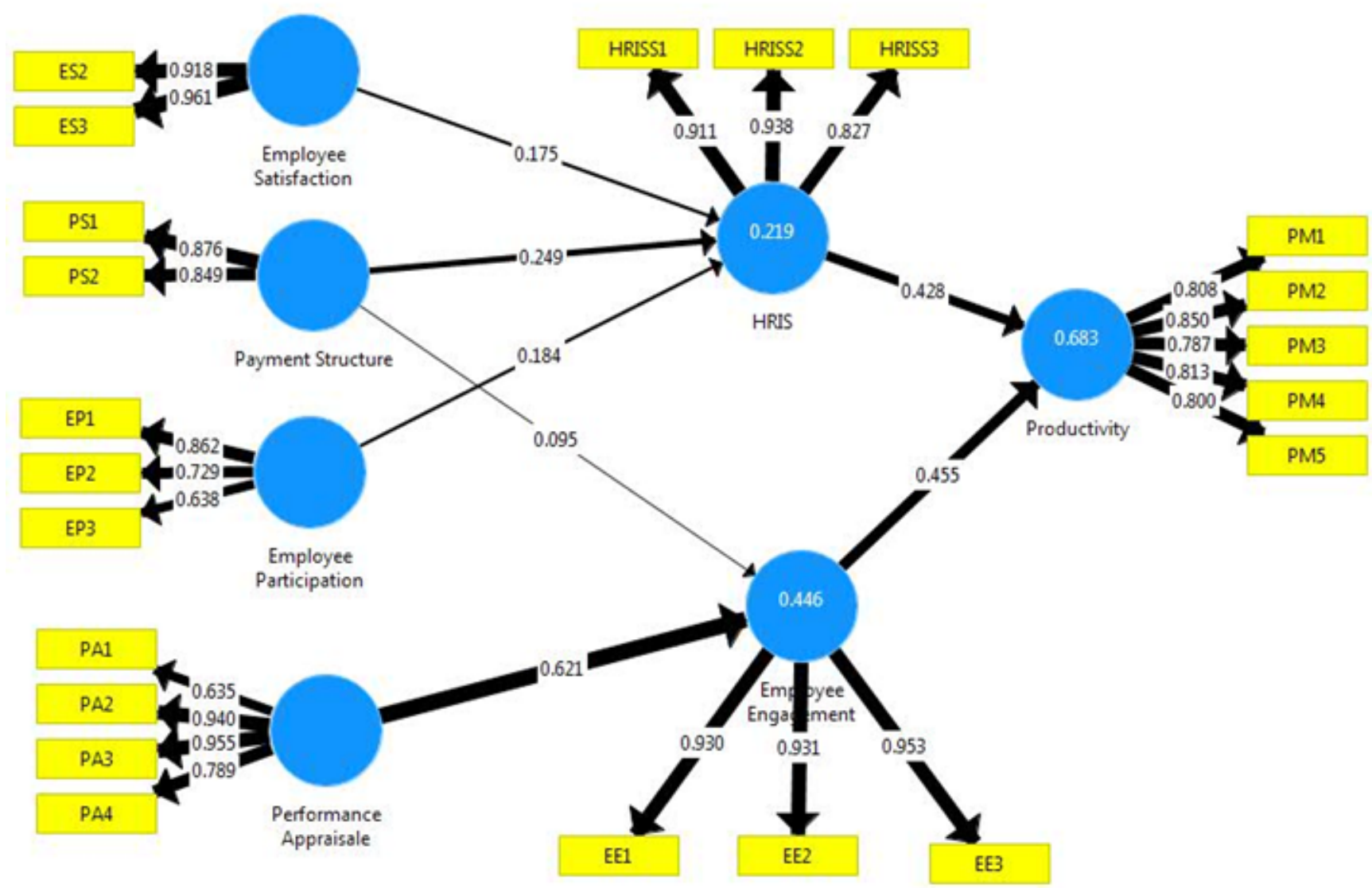

Figure 3: A schematic collinearity based SMART PLS model highlighting relative value as per their weightage of reflective

\section{Description about Conceptual model}

Variables evaluation and weightage has been done by applying the variance based Smart PLS method to generate the statistical values, which are stated above in the fig. 3. Although applying this software in Human Resource area is very interesting and new which also gives highly robust results.

Sander \& Lee (2014) clearly stated in his research paper about the usage of Smart PLS by defining its advantages, disadvantages and also used this method to explain the social sites surfed by the employment seekers for improving the recruiting methods used by the companies. 
Diffusion of Technology in strategic HR Practices and their impact over productivity of small firms

\# Description and interpretation of variables

\begin{tabular}{|c|c|c|}
\hline Code & Outer Variable (manifest) & Inner variable (Latent) \\
\hline $\begin{array}{l}\text { ES2 } \\
\text { ES3 } \\
\text { PS1 } \\
\text { PS2 } \\
\text { EP1 } \\
\text { EP2 } \\
\text { EP3 } \\
\text { PA1 } \\
\text { PA2 } \\
\text { PA3 } \\
\text { PA4 } \\
\text { HRISS1 } \\
\text { HRISS2 } \\
\text { HRISS3 } \\
\text { EE1 } \\
\text { EE2 } \\
\text { EE3 } \\
\text { PM1 } \\
\text { PM2 } \\
\text { PM3 } \\
\text { PM4 } \\
\text { PM5 }\end{array}$ & $\begin{array}{l}\text { Employee satisfaction } \\
\text { Payment structure } \\
\text { Employee Participation } \\
\text { Performance Appraisal } \\
\text { Motivation } \\
\text { Stress } \\
\text { High pay } \\
\text { Low Bonus } \\
\text { Informal } \\
\text { Ownership } \\
\text { Consultative } \\
\text { Improvement Plan } \\
\text { Quality } \\
\text { Self Evaluation } \\
\text { Performance record } \\
\text { Payroll } \\
\text { Data manage } \\
\text { Self Service } \\
\text { Personal Growth } \\
\text { Trust } \\
\text { Commitment } \\
\text { Creativity } \\
\text { Employee Satisfaction } \\
\text { Market Capture } \\
\text { Better Quality } \\
\text { Competitive Advantage }\end{array}$ & $\begin{array}{l}\text { HRIS } \\
\text { Employee engagement } \\
\text { Productivity (Dependent) }\end{array}$ \\
\hline
\end{tabular}

In the above there are two types of variable have been used by the researcher which includes the latent variable (inner variable) and manifest variables (outer variable). This model used only the endogenous latent variables.

The standardized path coefficient value has been mentioned on the arrows clearly mentioned the positive and direct relation with the latent variables.

\section{Cronbach's Alpha value, Total Effect and Discriminant value table}

Reliability check: For checking the consistency between the variables of the scale development we consider the Cronbach's alpha method whose value should be above the .7 for acceptability of the scale and reliability of their variables. If the value is lies between the .8 to .9 means the items are highly correlated. (Stephanie, 2014). Cronbach's Alpha value or Rho value for consistency checking of scale.

Table 1: Reliability \& Rho value table

\begin{tabular}{|l|c|c|c|c|}
\hline \multicolumn{1}{|c|}{ Variables } & Cronbach's Alpha & Rho Value & $\begin{array}{c}\text { Composite } \\
\text { Reliability }\end{array}$ & $\begin{array}{c}\text { Average } \\
\text { Variance }\end{array}$ \\
\hline Employee Engagement & .932 & .933 & .932 & .821 \\
\hline Employee participation & .599 & .662 & .626 & .368 \\
\hline Employee Satisfaction & .871 & .878 & .874 & .776 \\
\hline HRIS & .871 & .872 & .867 & .687 \\
\hline Payment Structure & .656 & .687 & .668 & .506 \\
\hline Performance appraisal & .854 & .870 & .860 & .609 \\
\hline Productivity & .877 & .895 & .864 & .571 \\
\hline
\end{tabular}




\begin{tabular}{|c|c|c|c|c|c|c|c|c|}
\hline \multicolumn{9}{|l|}{ Total Effects } \\
\hline \multirow[t]{2}{*}{ (11) Matrix } & \multicolumn{6}{|r|}{ Copy to Clipboard: } & \multirow[t]{2}{*}{ Excel Format } & \multirow[t]{2}{*}{ R Format } \\
\hline & Employee Eng... & Employee Parti. & Employee Satis... & HRIS & Payment Struc... & Performance A... & & \\
\hline Employee Enga.. & & & & & & & 0.368 & \\
\hline Employee Parti... & & & & 0.184 & & & 0.102 & \\
\hline Employee Satis... & & & & 0.153 & & & 0.085 & \\
\hline HRS & & & & & & & 0.558 & \\
\hline Payment Struct.. & 0.015 & & & 0.291 & & & 0.168 & \\
\hline Performance A... & 0.721 & & & & & & 0.265 & \\
\hline Productivity & & & & & & & & \\
\hline
\end{tabular}

Figure 5: Total Effect table generated by SMART PLS

In the above table, Payment structure and Employee Participation are the factors, which are showing their calculated value in red color because their calculated value is below the cut off value i.e. .7. The cut off value for all three indicators i.e. Cronbach's alpha, Rho value and Composite reliability is .7 and .5 for average variance. This means employee participation and payment structure are not showing good reliability. The above table described the Total values which is, as per the expected criteria, very good.

The discriminant validity report is very good. The criterion for having good report is the diagonal values should be greater than the correspondent vertical and horizontal values. In the above table in all the variables the above criteria is being fulfilled. For checking the discriminant analysis, the MSV should be greater than ASV or the square root of MSV should be greater than ' $r$ ' (coefficient of regression). In case of 'Employee engagement' above 0.906 is the square root of $\mathrm{MSV}$, which is greater than the correlations with the following variables- 0.478 (Employee participation), 0.368 (Employee satisfaction), 0.839 (HRIS), 0.451 (Payment structure), 0.730 (Performance) and 0.835 (Productivity), the same is true for the other variables and with the horizontal values too.

The performance appraisal factor has greater effect over the employee engagement latent variable because in comparison to other outer variable, it show the .621 calculated value which is greater than other path coefficient values.

The same employee engagement inner latent variable value i.e. .455 is greater than the HRIS path analysis value for supporting the good productivity variable.

The employee engagement has explained variance value is $\mathrm{R}=.446$ and HRIS is .219. The employee engagement factor has greater impact over productivity although HRIS also have a good impact but the calculated path coefficient value is .455 and .428 respectively. The dependent factor in the model is Productivity whose calculated $\mathrm{R}^{2}$ value is .683 . So, it is clearly stated in the end of the model that outer loading dependent value of all items are greater than the cut off value i.e.70 which is very good for construct reliability. So, this model is based on multiple regression and clearly supported the theory of the research paper.

\section{IMPLICATION AND LIMITATION}

This research study clearly revealed that the selected modern HR practices which were choose by referring the previous researches in the form of construct having an impact over the dependent variable i.e. productivity. Some construct variable having the great extent of impact while some others are having low impact over the productivity. While this study is only based on six human factor which can be changed in future for further study.

Some limitation of this research study is mentioned below;

1. Fear of loss of privacy of the respondents while filling the questionnaire.

2. Situation, timings and emotion at that time also affect the respondents in giving and representing their genuine response while filling the questionnaire.

3. This study is based on manufacturing industry of Delhi NCR region only but this can be further extended to some other regions and some other sectors for further research 4. Limited time, money and sample size in place of census survey are also the constraints for this research.

5. Unawareness about the up gradation in technology and their increased benefits in small firms

\section{CONCLUSIONS}

As a researcher this is very interesting to use the Smart Partial least square method in HR field because generally this method has been used in IT and marketing field to support the theory where the sample size is very small. In this study it is clearly revealed by applying the PLS SEM model that the HR practices having the positive effect over the output of small firms. But the long term and sustainable competitive advantage can be gained by strategically choose right method and practice at right time at right place. The result of this study has been concluded by applying the Smart PLS model, which shows that the six human factors selected by researcher based on whole organization point of view strategically having a good impact over the productivity in small firms. 


\section{ACKNOWLEDGEMENT}

The researcher thanks Prof. Gaurav Dawar for their special contribution and help in data analysis part by providing their guidance in application of Smart PLS software.

\section{REFERENCES}

[1] Ichniowski, C., Shaw, K., \& Prennushi, G. (1995). The effects of Human resource management practices on productivity. National Bureau of Economic Research

[2] Ulrich, D. (1997). Measuring Human Resources: An Overview of Practice and a Prescription for results. Human Resource Management 36 (3).

[3] Casse, C., Nadin, S., Gray, M., \& Clegg, C. (2002). Exploring human resource management practices in small and medium sized enterprises. Personnel Review, 31 .

[4] Wright, P. M., Gardner, T. M., \& Lisa, M. M. (2003). The Impact of HR practices on the performance of business units. Human Resource Management Journal , 13 (3), 21-36.

[5] Singh, K. (2004). Impact of HR practices on the perceived firm performance in India. Asian Pacific Journal of Human Resource , 42 (3).

[6] Bell, V. (2006). Productivity-The human factor. Retrieved from http://www.thefabricator.com:

https://www.thefabricator.com/article/shopmanagement/productivity-t he-human-factor

[7] Florkowski, G. W., \& Lujan, M. R. (2006). The diffusion of human-resource information-technology innovations in US and non US firms. Personnel Review .

[8] Singh, R. K. (2009). Welfare Measures and its impact Manpower Productivity. Retrieved from http://www.indianmba.com/Faculty_Column/FC992/fc992.html

[9] Singh, S., Darwish, T. K., Costa, A. C., \& Anderson, N. R. (2012, May). Measuring HRM and organisational performance: Concepts, issues, and framework. Management Decision .

[10] Abdulai, I. A., \& Shafiwu, A. B. (2014). Participatory Decision Making and Employee Productivity. A Case Study of Community Banks in the Upper East region of Ghana. Business and Economics Journal .

[11] Stephanie. (2014, December). Statistics How To. Retrieved from www.statisticshowto.datasciencecentral.com: https://www.statisticshowto.datasciencecentral.com/cronbachs-alphaspss/

[12] Sander, T., \& Lee, T. P. (2014). SmartPLS for the Human Resource Field to Evaluate a Model. New Challenges of Economic and Business Development -2014.

[13] Onyije, O. C. (2015). Effect of Performance Appraisal on Employee Productivity in a Nigerian University. JOURNAL OF ECONOMICS AND BUSINESS RESEARCH , 21 (2).

[14] Katou, A. A., \& Budhwar, P. (2015). Human resource management and organisational productivity: A systems approach based empirical analysis. Journal of Organizational Effectiveness: People and Performance, 2 (3).

[15] Gamage, A. S. (2015). The Role of HRM in Improving Labour Productivity: An Analysis of Manufacturing SMEs in Japan. Sri Lankan Journal of Human Resource Management, 5.

[16] Flores, H. (2017). How HRIS Can Harness Maximum Productivity Yes, It can be done! Retrieved from http://www.paydayonesource.com/:

http://www.paydayonesource.com/hris-can-harness-maximum-produc tivity-yes-can-done/

[17] Stone, D. L., Deadrick, D. L., Lukaszewski, K. M., \& Johnson, R. (2015). The In fl uence of Technology on the Future of Human Resource Management. Human Resource Management Review

[18] Ahmed, H. M. (2016). Technology in Performance Appraisal System with Specific Reference to Group of Companies HSA and its Partners in the Republic of Yemen. IBMRD's Journal of Management \& Research , 5 .

[19] Sarangi, D., \& Nayak, D. (2016). Employee Engagement and Its Impact on Organizational Success - A Study in Manufacturing Company, India. Journal of Business and Management , 18 (4), 52-57.

[20] Sea, N. (2017, October). RiseSmart. Retrieved from www.risesmart.com: https://www.risesmart.com/blog/5-ways-hr-can-improve-employee-pr oductivity

[21] Mayhew, R. (2018). Functions \& Practices of Human Resource Management. Retrieved from smallbusiness.chron.com: https://smallbusiness.chron.com/functions-practices-human-resourcemanagement-59787.html
[22] Pandey, A. (2018). Role of Artificial Intelligence in HR. Retrieved from pcquest.com: https://www.pcquest.com/role-artificial-intelligence-hr/

[23] Bun, M. J., \& Huberts, L. C. (2018). The Impact of Higher Fixed Pay and Lower Bonuses on Productivity. Journal of Labor Research , 39 (1), 1-21.

[24] Bhardwaj, S., \& Jain, A. (2019). Role of Human Resource Management in Small Scale Electrical industries of Delhi NCR Regions. Journal fo Advance Research in Dynamical \& Control Systems , 1145-1158. 